\title{
The Effect of Parathyroid Hormone on the Renal Accumulation of Lead ${ }^{1}$
}

\author{
David R. Mouw ${ }^{2}$ Judy G. Wagner, Ken Kalitis, Arthur J. Vander, \\ and Gilbert H. Mayor \\ Department of Physiology, University of Michigan. Medical School, Ann Arbor. \\ Michigan 48109
}

Received November 28, 1976

\begin{abstract}
The effect of parathyroid hormone (PTH) on renal accumulation of lead has been assessed in two experiments on mature rats. In the first experiment, lead was given per os, followed by subcutaneous injections of PTH (100 units of parathyroid extract. Lilly) or vehicle alone over the next 2 days. In the second experiment, anesthetized rats were given lead \pm PTH (bovine 1-34, Beckman: primed with $1.33 \mu \mathrm{g}$ and a constant infusion of $4.2 \mathrm{ng} /$ minute) intravenously over a 2-hour period. In both experiments, PTH caused significant increments in renal lead concentration ( 52 and $29 \%$, respectively) compared to groups treated with lead but not PTH. Since total body lead is also increased with PTH treatment in the first experiment, a gastrointestinal (GI) mechanism is suggested; however, stimulation of GI absorption cannot account for the effect in the second experiment in which lead was administered iv. In both experiments, the increment in renal lead in the absence of changes in lead in other soft tissues (liver, red cell. or plasma) suggests a selective effect of PTH on renal lead. The possible mechanisms for this effect are discussed.
\end{abstract}

\section{INTRODUCTION}

Reductions in dietary calcium of experimental animals potentiate not only the retention of dietary calcium but also dietary lead (Sobel et al., 1970; Shields and Mitchell, 1941; Six and Goyer, 1970; Mahaffey and Goyer, 1973; Barltrop and Khoo, 1975); the general increase in body lead probably results from increased gastrointestinal absorption of lead (Barltrop and Khoo, 1975; Mahaffey, 1974). It has been hypothesized that similar mineral deficiencies may also play a significant role in the etiology of childhood lead poisoning (Mahaffey, 1974). Interestingly, iron-deficient diets also potentiate lead retention in animals (Six and Goyer, 1972), and it seems likely that other divalent cations such as Mg (Krall et al., 1974), may also affect lead retention. Previous investigators have contrived iron and calcium deficiencies in lead-poisoned rats so that they produced similar threefold increments in bone lead (compared to animals on normal diet plus lead) over a 10-week experiment (Six and Goyer, 1970, 1972; Mahaffey and Goyer, 1973). Since bone is the major storage site of lead (over $90 \%$, Hammond et al., 1972), the results implied that overall body retention and net gastrointestinal uptake of lead were similarly affected by the calcium and iron deficiency. There was, however, a major difference in the retention pattern in the two deficient groups: iron deficiency increased renal lead from 14.5 to $38.7 \mu \mathrm{g} / \mathrm{g}$ (2.7-fold; i.e., similar to the

\footnotetext{
${ }^{1}$ Supported by Grant 1 ROI ESOl141 from the National Institutes of Environmental Health Sciences.

2 Send reprint requests to Dr. Mouw.
} 
effect on bone retention); calcium deficiency, however, increased renal lead from 29.6 to $691 \mu \mathrm{g} / \mathrm{g}$ (23-fold).

The above results led us to hypothesize that parathyroid hormone (PTH), which would be elevated in calcium deficiency but presumably not in iron deficiency, would cause a specific increase in the ratio renal lead/total body lead. Thus, the objectives of this study were to determine whether administration of PTH causes increased renal lead accumulation and to ascertain if this effect is independent of changes in the gastrointestinal handling of lead. We administered lead per os to unanesthetized (experiment $A$ ) or intravenously to anesthetized rats (experiment B); in both cases, PTH caused a significant increase in the renal accumulation of lead.

\section{MATERIALS AND METHODS}

Experimental protocols. In experiment A, 24 male Sprague-Dawley rats $(250-300 \mathrm{~g})$ were housed individually and divided into groups 1 (lead), 2 (lead and $\mathrm{PTH}$ ), and 3 (PTH). On Day 1 of the study, groups 1 and 2 were given $40 \mathrm{mg}$ of lead (as lead acetate) in $20 \mathrm{ml}$ of water at 2100 hours while group 3 received only water at this time. All three groups had been deprived of water for the 24 hours prior to this time to ensure complete intake of the fluid. On Days 2 and 3 of the study, all rats were given water ad libitum. Groups 2 and 3 were given subcutaneous injections of parathyroid extract (Lilly, USP) in an aqueous vehicle containing $15 \%$ gelatin, $0.1 \%$ phenol, and $0.8 \%$ glycerin. Injections of 25 units $(0.5 \mathrm{ml})$ were given according to the following schedule: Day 1 at 1700 hours (4 hours prior to lead availability), Day 2 at 700 and 1700 hours, and Day 3 at 700 hours. Group 1 was injected with the vehicle alone at these same times. All three groups were fed standard rat chow (Teklad) throughout. All rats were weighed and anesthetized with pentobarbital $(50 \mathrm{mg} / \mathrm{kg}$ ) between 1300 and 1500 hours on the third day. Blood was collected from the abdominal aorta: the liver, the kidneys, and a femur were removed. Plasma, kidney, and liver were analyzed for $\mathrm{Ca}^{2+}$, and $\mathrm{Pb}^{2+}$ content; erythrocytes and the diaphyseal portion of the femur were also analyzed for bonc lead.

In experiment $\mathrm{B}, 14$ male rats weighing $290-330 \mathrm{~g}$ were divided into two groups; the mean weight of group 1 was $315.7 \pm 3.9 \mathrm{~g}$ and that of group 2 was 314.5 $\pm 4.01 \mathrm{~g}$ (not significantly different). Prior to the experiment, animals had been fed standard rat chow (Teklad) with water ad libitum. The rats were anesthetized with pentobarbital $(50 \mathrm{mg} / \mathrm{kg}$ body weight) given intraperitoneally with supplements $(0.05 \mathrm{ml}$ of $50 \mathrm{mg} / \mathrm{ml})$ given intra-arterially throughout the experiment as required; immediately after onset of anesthesia, each rat also received one subcutaneous injection of atropine $(0.2 \mathrm{ml}$ of $4 \mathrm{mg} / \mathrm{ml}$ in saline $)$ in order to reduce airway secretions. The surgery consisted of a tracheostomy, cannulation of both the femoral artery and the femoral vein in one leg with PE 50 tubing, and placement of a flared cannula (PE 200) in the upper portion of the bladder with the cannula tip near the opening to the ureters. After surgery, group 1 ("Pb only") and group 2 ("PTH and $\mathrm{Pb}$ ") were subjected to the following protocols lasting 4.5 hours. Throughout the entire protocol, all rats received an isotonic saline infusion into the femoral artery at the rate of $39 \mu \mathrm{l} /$ minute. After the first 1.5 hours, group 2 also received synthetic PTH (bovine 1-34, Beckman) in the femoral vein; a prime of 
PTH (1.334 $\mu \mathrm{g}$ in $0.2 \mathrm{ml}$ of saline over 2 minutes) was followed by a constant infusion of PTH (42 ng/minute in saline, $6.25 \mu \mathrm{l} /$ minute) for the remaining 3 hours of the experiment. During the last 2 hours of the experiment lead acetate was added to the saline infusion of both groups (to produce a lead concentration of 200 $\mu \mathrm{g} / \mathrm{ml}$ ): since the rate of saline infusion was not altered, the total lead dose per rat was $936 \mu \mathrm{g}$ over the 2 hours. Throughout the experiment, arterial blood pressure and heart rate were monitored via a three-way connector in the arterial catheter leading to a Statham pressure transducer and Grass polygraph; mean pressure was recorded at 0.5 -hour intervals for statistical evaluation. Urine was collected during the period of lead infusion (last 2 hours of the experiment) in two animals from each group. Rectal temperature was monitored and maintained between $36-37^{\circ} \mathrm{C}$ using heat lamps. At the conclusion of the experiments all rats were bled from the abdominal aorta to determine hematocrit, red cell lead, plasma lead, and plasma $\mathrm{Ca}^{2+}$; both kidneys and the liver were removed and their lead contents determined.

Analytical techniques. Lead analysis was performed by atomic absorption spectrophotometry (AAS) (Yeager et al. 1971) as previously reported (Mouw et al., 1975). Our detection limits are defined as the concentration of lead in the tissue that can be detected with a $95 \%$ certainty. Statistically, then, it is the concentration that gives a reading twice the standard deviation of a series of blanks. Different detection limits (micrograms per gram) for different tissues reflect differences in the weight of the tissue sample. Kidney and liver $\mathrm{Ca}^{2+}$ were measured according to standard methods in AAS (Perkin-Elmer) as was plasma $\mathrm{Ca}^{2+}$. Both lead and calcium were measured on digests of whole kidney.

\section{RESULTS}

In both experiments $\mathrm{A}$ and $\mathrm{B}, \mathrm{PTH}$ administration to lead-treated animals caused hypercalcemia; plasma calcium rose from 5.08 to 6.37 mequiv/liter in experiment A (Table 1) and from 4.59 to 4.90 mequiv/liter in experiment $B$ (Table 2). Table 1 summarizes the results for the other measured variables in experiment A. In lead-fed animals (groups 1 and 2), PTH treatment caused a 52\% increase in renal lead which was significant at the 0.06 level. Bone lead was also increased $(31.6 \%)$, but lead levels in liver and red cells were not affected by PTH treatment. Kidney calcium was elevated approximately $25 \%$ in the animals treated with lead and PTH (group 2) compared to either treatment alone (groups 1 and 3). Finally, PTH caused a $13 \%$ decrease in liver weight.

Table 2 summarizes the data collected from the animals at the conclusion of experiment B. Hematocrits, kidney weights, and liver weights were not different in the two groups. Renal lead was $29 \%$ higher in the PTH-treated animals. Red cell, plasma, and liver lead were not different in the two groups; bone lead was undetectable $(<1 \mu \mathrm{g} / \mathrm{g})$ in both groups. Although there was much variability in the plasma lead between individual animals (see Discussion for explanation), there was no correlation of plasma lead with kidney lead in either group. Blood pressure was not significantly affected by lead either in the presence or absence of PTH; moreover, there were no significant differences in blood pressure between groups 1 and 2 during the 2-hour lead infusion (group $1=120.6 \pm 6.1$, group $2=124.3 \pm$ 3.7). Heart rate was also unaffected by the experimental manipulations (mean 
TABLE 1

Effect of PTH ox Renal Lead Retention and Other Biological Variables in Unanestheitzed Rats (Experiment A)"

\begin{tabular}{|c|c|c|c|c|c|}
\hline & $\begin{array}{l}\text { Group } 1 \\
\mathrm{~Pb} \text { only }\end{array}$ & $\begin{array}{c}P \text { value } \\
\text { ( } \mathrm{Pb} \text { only } \\
\text { vs } \mathrm{Pb} \pm \mathrm{PTH} \text { ) }\end{array}$ & $\begin{array}{c}\text { Group } 2 \\
\mathrm{~Pb}+\mathrm{PTH}\end{array}$ & $\begin{array}{c}P \text { value } \\
(\mathrm{Pb}+\text { PTH vs } \\
\text { PTH only) }\end{array}$ & $\begin{array}{l}\text { Group } 3 \\
\text { PTH only }\end{array}$ \\
\hline $\begin{array}{l}\text { Kidney } \mathrm{Pb} \\
(\mu \mathrm{g} / \mathrm{g})\end{array}$ & $5.41 \pm 0.645$ & 0.06 & $8.21 \pm 1.17$ & $<0.001$ & $<1.0 \quad(\mathrm{ND})^{\prime \prime}$ \\
\hline $\begin{array}{l}\text { Kidney weight } \\
\text { (g) }\end{array}$ & $2.50 \pm 0.08$ & NS & $2.35 \pm 0.103$ & NS & \\
\hline $\begin{array}{l}\text { Liver } \mathrm{Pb} \\
(\mu \mathrm{g} / \mathrm{g})\end{array}$ & $1.44 \pm 0.44$ & NS & $1.60 \pm 0.27$ & $<0.001$ & $<0.5 \quad$ (ND) \\
\hline $\begin{array}{l}\text { Liver weight } \\
\text { (g) }\end{array}$ & $11.95 \pm 0.43$ & $<0.02$ & $10.56 \pm 0.26$ & NS & $10.89 \pm 0.31$ \\
\hline $\begin{array}{l}\text { Total liver } \mathrm{Pb} \\
\quad(\mu \mathrm{g}) \\
\text { Red cell lead }\end{array}$ & $16.40 \pm 4.23$ & NS & $16.56 \pm 2.35$ & $<0.001$ & $<5.5$ \\
\hline $\begin{array}{l}\text { Red cell lead } \\
(\mu \mathrm{g} / \mathrm{g}) \\
\text { Bone lead }\end{array}$ & $1.53 \pm 0.28$ & NS & $1.67 \pm 0.29$ & $<0.001$ & $<0.10$ (ND) \\
\hline $\begin{array}{l}\text { ( } \mu \mathrm{g} / \mathrm{g} \text { wet weight) } \\
\text { Plasma } \mathrm{Ca}^{2+}\end{array}$ & $15.49 \pm 1.30$ & $<0.05$ & $20.39 \pm 1.60$ & $<0.001$ & $<4.0 \quad(\mathrm{ND})$ \\
\hline $\begin{array}{l}\text { (mequiv/liter) } \\
\text { Kidney } \mathrm{Ca}^{2+}\end{array}$ & $5.08 \pm 0.02$ & $<0.001$ & $6.37 \pm 0.08$ & NS & $6.13 \pm 0.12$ \\
\hline $\begin{array}{l}\quad(\mu \mathrm{g} / \mathrm{g}) \\
\text { Liver } \mathrm{Ca}^{2+}\end{array}$ & $104.8 \pm 1.89$ & $<0.001$ & $130.6 \pm 3.27$ & $<0.001$ & $106.0 \pm 3.32$ \\
\hline $\begin{array}{c}(\mu \mathrm{g} / \mathrm{g}) \\
\text { Body weight }\end{array}$ & $42.66 \pm 2.78$ & NS & $46.16 \pm 2.25$ & NS & $49.06 \pm 1.55$ \\
\hline (g) & $270.9 \pm 4.49$ & NS & $265.4 \pm 3.57$ & 0.07 & $276.5 \pm 4.54$ \\
\hline $\begin{array}{l}\text { Hemotocrit } \\
(\%)\end{array}$ & $38.9 \pm 1.09$ & NS & $40.7 \pm 0.68$ & NS & $41.0 \pm 0.96$ \\
\hline
\end{tabular}

values for the final 2 hours of the experiment for groups 1 and 2 were $398.9 \pm 7.16$ and $394.6 \pm 8.00$ beats/minute, respectively). Urinary lead excretion measured over the 2 hours of lead infusion in two animals from each group was undetectable (less than $0.5 \mu \mathrm{g} / \mathrm{ml}$ ) in all four animals; the excretory rate was calculated to be less than $0.6 \mu \mathrm{g} / \mathrm{hour}$ in each of these four animals.

\section{DISCUSSION}

These experiments demonstrate that parathyroid hormone can increase the renal accumulation of lead and that this effect is not due solely to enhanced gastrointestinal absorption of lead. In experiment $A$, the contribution of increased gastrointestinal reabsorption cannot be discounted since the rats received lead per os plus continuous exposure to elevated levels of PTH over 41 hours. Since both bone (the major body lead store) and kidney lead were elevated (by 32 and $52 \%$, respectively), PTH clearly increased total body lead retention. If one assumes that net GI absorption of the ingested lead has been completed at the time of sacrifice, that virtually all lead is in bone, that the femur is representative bone sample, and 
TABLE 2

Effect of Intravenolsly Administerfod Parathyroid Hormone (Bovine 1-34) During a 2-Hour Aclite Lead Exposcre in Axesthetized Rats (Experiment B) ${ }^{h}$

\begin{tabular}{lcr}
\hline & I & \multicolumn{1}{c}{ II } \\
& \multicolumn{1}{c}{ Pb only } & PTH and Pb \\
\hline Plasma Ca $a^{2+}$ (mequiv/liter) & $4.59 \pm 0.07^{\circ}$ & $4.9 \pm 0.11$ \\
Hematocrit $(c / c)$ & $45.66 \pm 1.63$ & $46.81 \pm 1.23$ \\
Kidney weight $(\mathrm{g})$ & $2.33 \pm 0.08$ & $2.32 \pm 0.10$ \\
Liver weight $(\mathrm{g})$ & $10.58 \pm 0.36$ & $10.75 \pm 0.40$ \\
Kidney lead $(\mu \mathrm{g} / \mathrm{g})$ & $14.72 \pm 1.19^{b}$ & $18.96 \pm 1.02$ \\
Liver lead $(\mu \mathrm{g} / \mathrm{g})$ & $20.43 \pm 3.00$ & $20.71 \pm 2.45$ \\
RBC lead $(\mu \mathrm{g} / \mathrm{g})$ & $6.00 \pm 0.51$ & $6.14 \pm 0.69$ \\
Plasma lead $(\mu \mathrm{g} / \mathrm{ml})$ & $4.96 \pm 1.30$ & $4.64 \pm 1.26$ \\
\hline
\end{tabular}

"Each value is the mean $\pm \mathrm{SE}$.

${ }^{b} P<0.03$.

that bone weight is $7.5 \%$ of body weight, then net GI absorption of lead is calculated to be $1.01 \%$ for the PTH-treated group and $0.79 \%$ for the control group; this agrees well with GI absorption rates for lead in rats, as similarly calculated from the data of other groups (Six and Goyer, 1970, 1972). The mechanism for this PTH effect on net GI absorption cannot be determined from our experiments, but one possibility is the stimulatory effect of PTH on renal activation of vitamin D (Rasmussen et al., 1972; Hill and Stanbury, 1975); vitamin D in turn would increase GI absorption of lead (Sobel et al., 1970). To reiterate, experiment A demonstrates a stimulatory effect of PTH on renal lead accumulation, but does not prove that PTH acts directly to stimulate renal uptake of lead, since GI uptake was also increased; the results from experiment B thus become crucial in testing our hypothesis. However, the fact that bone and kidney lead are increased by PTH in experiment A but liver and red cell lead are not, suggests that PTH does have some specific effect on the kidney compared to other soft tissues.

In experiment B, lead was administered intravenously and any effect of PTH on GI absorption of lead can be ruled out. Nevertheless, over a brief (2-hour) period, PTH caused a $29 \%$ increase $(P<0.03)$ in renal lead. Thus PTH substantially alters renal lead accumulation over a short time period despite identical lead input to the blood pool in both groups 1 and 2. The kidneys of the group 2 (PTH-treated) animals contain $9.75 \mu \mathrm{g}$ more lead $[2.3 \mathrm{~g}$ of kidney times $(18.96-14.72 \mu \mathrm{g} / \mathrm{g})]$ than kidneys from group 1 animals. The source of this lead cannot be discerned in our experiments. The $9.75 \mu \mathrm{g}$ of lead is about $1 \%$ of the total of $936 \mu \mathrm{g}$ infused, and thus, if we assumed that the kidneys simply accumulated this much extra from the blood and that all other tissues thus received $1 \%$ less, the decrement in other tissues would be undetectable by our analytical methods.

The mechanism by which PTH increases the amount of lead in the kidney, but not other soft tissues, is not clear from these experiments. Present concepts of the renal handling of lead are currently undergoing revision. We have recently observed in stop-flow experiments (Victery et al.. 1976) that acutely administered lead is reabsorbed in the proximal and distal tubules: we have found no evidence for net tubular secretion. In subsequent experiments using $203 \mathrm{~Pb}$ in dogs, we 
have demonstrated that an acute dose of $\mathrm{Pb}$ is handled by filtration and reabsorption (submitted for publication). These findings suggest that renal filtration and reabsorption account for the renal excretion of lead. Assuming such a mechanism for renal lead excretion and assuming that part of the reabsorbed lead were to remain in the tubular cells, one can make four hypotheses for the action of PTH: (1) It may simply enhance the rate of tubular reabsorption without changing the amount filtered; (2) it may increase the amount filtered, thereby leading to enhanced reabsorption; (3) it may retard the exit of lead from the cell, once lead crosses the luminal membrane; or (4) it may increase lead movement from peritubular capillaries into the tubular cell. We will discuss these four hypotheses in turn.

Our experiments provide evidence against the hypothesis that PTH increases renal lead by stimulating reabsorption in the absence of increased filtration. Urinary excretion of lead was very low (less than $0.6 \mu \mathrm{g} /$ hour) in the absence of PTH and is comparable to that reported by others in acute experiments employing a similar dose of lead (Klassen and Shoeman, 1974) or for chronic experiments in which the oral administration of lead resulted in similar levels of renal lead (Boyer et al., 1970). Since lead excretion is so low over the 2 hours of lead exposure in group 1 (no PTH), it is impossible that increased renal lead resulted from an effect of PTH on lead reabsorption alone. Even if all the lead which would have been excreted over the 2 hours of lead infusion (less than $1.2 \mu \mathrm{g}$ ) were to be retained during the PTH infusion in group 2 animals, it could not account for the absolute increment in renal lead $(9.75 \mu \mathrm{g})$. Thus, without an increase in filtered lead, increased tubular reabsorption of lead cannot account for the PTH effect on renal lead in experiment $B$.

Our experiments provide no evidence concerning the second hypothesis, namely, that PTH might increase the filtration of lead at the glomerulus, thereby providing increased lead to the reabsorptive process. Plasma lead varied widely between animals in experiment B; acute lead dose-response studies (Klassen and Shoeman, 1974) have shown that a small change in lead dose causes a disproportionately large change in plasma lead at the dose range used in our experiments. Since the rats in experiment $B$ each received the same amount of lead, the actual dose rate varied slightly, accounting for the variable plasma lead. Despite this wide variation of plasma lead in both groups of experiment $B$, there was no correlation of plasma lead and renal lead in either or both groups. However, this does not prove there was no correlation between ultrafilterable lead (not measured) and renal lead. Since only a tiny fraction of the plasma lead is ultrafilterable at these high plasma lead levels (personal observation), large changes in ultrafilterable lead would not necessarily be related to changes in total plasma lead. Besides possibly raising the filterability of lead. PTH might increase lead filtration by raising the glomerular filtration rate (GFR). PTH has been shown to cause acute increases in renal blood flow (RBF) and variable changes in the GFR (see Massry et al.. 1975. for review); unfortunately GFR was not measured in our experiments. Over the 2 hours of lead infusion, the average blood pressure of individual animals, which might influence RBF and GFR, showed no correlation to renal lead in either group or in both groups combined. 
The third hypothesis is that PTH retards the exit of lead from the tubular cell after it crosses the luminal membrane. A mechanism by which this could occur is suggested by the parallel changes occurring in renal calcium and renal lead in expcriment A (Table 1). Group 2, treated with a combination of lead and PTII had a renal calcium level higher than the groups treated with $\mathrm{Pb}$ or PTH alone; group 2 also had the highest renal lead level. The absence of similar changes in the liver suggests an interaction of lead, calcium, and PTH specifically in the renal tubular cell. These effects may be explained by the postulated effects of PTH on cellular transport of calcium (Massry et al., 1975); PTH is thought to increase cytosol calcium both by causing increased efflux of calcium from the mitochondrial store and by stimulating cellular uptake of calcium from the plasma (Rasmussen $e t \mathrm{al}$., 1972; Massry et al.. 1975). These effects of PTH increase cell calcium, particularly in the cytosol; cytosol calcium, however, would continue to reform the calcium phosphate complex in the mitochondria. Since lead increases the precipitation of calcium phosphate in vitro (Fleish et al., 1965), lead, passing into the cytosol across the luminal membrane of the tubular cell, might have a calcium-retaining effect on renal cells particularly in the presence of PTH. Meanwhile, the increased availability of phosphate resulting from PTH stimulation of calcium phosphate breakdown in mitochondria might also increase retention of $\mathrm{Pb}$-phosphate in renal cells. Lead phosphate formation would also be favored by the elevated levels of calcium, since calcium lowers the solubility of lead phosphate (Tice, 1969). Such an interaction of $\mathrm{Pb}, \mathrm{Ca}$, and $\mathrm{PTH}$ would be expected in renal tubular cells but not in liver cells as a result of the continued filtration and reabsorption of lead (across the luminal membrane) occurring only in the former organ. The effect of lead plus PTH on kidney calcium suggests the possibility that chronic lead poisoning might contribute to the etiology of renal diseases characterized by calcium accumulation. Interestingly, low calcium diets (which would be associated with high PTH levels) also cause increased renal calcium levels in lead-poisoned animals, but not in animals fed a calcium-deficient diet without lead. Thus, if PTH treatment (in our experiments) is equated with calcium deficiency (Six and Goyer, 1970; Mahaffey and Goyer, 1973), the effects on renal calcium of the lead-poisoned rat are analogous.

Finally, the fourth hypothesis is that PTH might increase the movement of lead across the peritubular membrane into the tubular cell. It has been demonstrated that lead can cross from peritubular capillaries into luminal fluid (Vostal and Heller, 1968; Victery et al.. 1976); thus lead must either permeate the peritubular membrane into the cell or pass between cells. If lead can cross the peritubular membrane, PTH might somehow potentiate this transport, leading to an elevation in renal lead. Further experiments will be necessary to distinguish between these four (and other) hypotheses on the mechanism by which PTH stimulates renal lead accumulation.

\section{ACKNOWLEDGMENT}

The authors express their sincere appreciation to Dr. Rolf Hartung of the School of Public Health. University of Michigan, for his help in developing and verifying our methods of lead analyses. 


\section{REFERENCES}

Barltrop, D., and Khoo, H. E. (1975). Nutritional determinants of lead absorption. In "Ninth Annual Conference on Trace Substances in Environmental Health," University of Missouri, June 9-12.

Fleish, H., Bisaz, S., and Russel, R. (1965). The activating effect of lead on the precipitation of calcium phosphate. Proc. Soc. Exp. Biol. Med. 118, 882-884.

Goyer, R. A., et al. (1970). Lead dosage and the role of the intranuclear inclusion body. Arch. Environ. Health 20, $705-711$.

Hammond, P. B.. et al. (Eds.) (1972). "Airborne Lead in Perspective." NRC-NAS, Washington, D.C.

Hill, L. F.. and Stanbury. S. W. (1975). Vitamin D and the kidney. Nephron 15, 369-386.

Klassen, C. D., and Shoeman, D. W. (1974). Biliary Excretion of lead in rats, rabbits, and dogs. Toxicol. Appl. Pharmacol. 29, 434-446.

Krall, A. R., Ganble, H. F., and Rogers, E. W. (1974). Hypomagnesemia and lead poisoning in dogs and rats. (Abstract). Fed. Proc. 33, 608.

Lederer. L. B.. and Bing, F. C. (1940). Effect of calcium and phosphorus on retention of lead by growing organisms. Amer. Med. Assoc. 114, 2457-2461.

Mahaffey, K. R. (1974). Nutritional factors and suseptibility to lead toxicity. Environ. Health Perspec. May, $107-112$.

Mahaffey, K. R., and Goyer, R. A. (1973). Dose-response to lead ingestion in rats fed low dietary calcium. J. Lab. Clin. Med. 82, 92-100.

Massry, S. G., et al. (1975). Relationship between the kidney and parathyroid hormone. Nephron 15 , 197-222.

Mouw, D. R., et al. (1975). Lead: Possible toxicity in urban vs nual rats. Arch. Environ. Health 30, $276-280$.

Rasmussen. H., et al. (1972). Cyclic AMP, calcium, and cell activation. In "Calcium. Parathyroid Hormone, and the Calcitionins" (Talmage and Munson, Eds.), pp. 492-500. Excerpta Medica, Amsterdam.

Shields, J. B., and Mitchell, H. H., (1941). The effect of calcium and phosphorus on the metabolism of lead. $J$. Nutr. 21, 541-552.

Six, K. M., and Goyer, R. A., (1970). Experimental enhancement of lead toxicity by low dietary calcium. J. Lab. Clin. Med. 76, 933-942.

Six, K. M., and Goyer, R. A. (1972). The influence of iron deficieney on tissue content and toxicity of ingested lead in the rat. J. Lab. Clin. Med. 79, 128-136.

Sobel, A. E., et al. (1970). The biochemical behavior of lead. I. Influence of calcium, phosphorus, and vitamin D on lead in blood and bone. J. Biol. Che'm. 132, $239-265$.

Tice, L. W. (1969). Lead-adenosine triphosphate complexes in adenosine triphosphatase histochemistry. J. Histochem. Cytochem. 17, 85-94.

Victery, W., Vander, A. J., and Mouw. D. R. (1976). Renal tubular handling of lead in dog. (Abstract). Fed. Proc. 35, 849.

Vostal, J., and Heller. J. (1968). Renal excretory mechanisms of heavy metals Transtubular transport of heavy metal ions in the avian kioney. Environ. Res. 2, 1-10.

Yeager, D. W., Cholak. J., and Henderson, E. W. (1971). Determination of lead in biological and related material by atomic absorption spectrophotometry. Environ. Sci Technol. 5, 1020-1022. 